\title{
The effect of RU486 administered during the proliferative and secretory phase of the cycle on the bleeding pattern, hormonal parameters and the endometrium
}

\author{
M.L.Swahn, E.Johannisson', V.Daniore, \\ B.de la Torre and M.Bygdeman \\ Department of Obstetrics and Gynaecology, Karolinska Hospital, \\ S-104 01 Stockholm, Sweden and 'Laboratory of Analytical and \\ Quantitative Cytology, Geneva, Switzerland
}

Seventeen healthy women aged $24-45$ years with regular menstrual periods, proven fertility and not using steroidal contraceptives or IUD were recruited for the study. The volunteers were followed during one control, one treatment and one follow-up cycle. Daily morning urine samples were obtained during the control and the treatment cycle. The samples were analysed with regard to pregnanediol glucuronide $\left(\mathrm{P}_{2}-\mathrm{G}\right)$, oestrone glucuronide $\left(\mathrm{E}_{1}-\mathrm{G}\right)$, oestradiol $\left(\mathrm{E}_{2}\right)$, progesterone $\left(\mathrm{P}_{4}\right), \mathrm{LH}$ and creatinine. During the entire 3-month study the subjects kept a record of uterine bleeding and side effects. The subjects received $50 \mathrm{mg}$ RU486 daily either on cycle days 7-10 $(n=7)$ or on cycle days $20-23$ $(n=10)$. An endometrial biopsy was taken on cycle day 10 in the first group and on cycle days $21-28$ in the second group of patients. Treatment during the proliferative phase caused significant prolongation of the cycle length due to a delay of the oestrogen and LH surge. However, once the oestrogen concentration started to increase, the remaining part of the cycle was normal. The length of the follow-up cycle was similar to that of the control cycle. The morphology of the endometrium did not differ from control samples taken from untreated women at the same time of the cycle. All ovulating women $(n=9)$ treated in the mid-luteal phase started to bleed on the 3rd to 4th day of the treatment. In four of these women the bleeding was scanty and followed by a menstrual-like bleeding at expected time, while in the remaining five volunteers the treatment bleeding was heavier and not followed by a new bleeding until a month later. The duration of the secretory phase was $16.5 \pm 1.3$ days in women with two bleeding episodes and $11.8 \pm 1.9$ days in women with one bleeding episode $(P<0.05)$. The hormonal parameters were similar in both groups up to the start of the treatment. In the patients with one bleeding episode, the treatment was associated with a reduction in progesterone concentration, while in the patients with two bleeding episodes the progesterone concentration remained elevated until the second bleeding episode. Light microscopic examination of the endometrium revealed unique changes in the endometrial morphology. The results indicate that RU486 acts mainly on the endometrium but a direct or indirect effect on the corpus luteum cannot be excluded. The age of the corpus luteum may be of importance for its susceptibility to RU486 treatment.
Key words: antiprogestin/bleeding pattern/endometrial morphology/menstrual cycle

\section{Introduction}

The presence of a normal corpus luteum, secreting adequate levels of progesterone, is a prerequisite for implantation of the fertilized ovum and for the maintenance of very early pregnancy, both in animals and in the human. Compounds which interfere with corpus luteum function, the production of progesterone or its effect on the target organ are therefore potential candidates for use in a postovulatory mode of fertility control.

Prostaglandin $\mathrm{F}_{2 \alpha}$ has been shown to be luteolytic in many animal species (Pharris, 1971; McCracken et al., 1972; Behrman, 1979). However, it has not been possible so far to demonstrate such an effect in the human. Intermittent, mid-luteal administration of LHRH agonist has been shown to be capable of causing a decrease in serum progesterone levels and premature onset of menstruation (Bergquist et al., 1980a), but the timing of the LHRH agonist treatment seemed, however, to be critical for its effectiveness (Bergquist $e t$ al., 1980b). This fact, together with the finding that simultaneous administration of HCG prevented the luteolytic effect of the agonist, indicates that it is unlikely that these types of compounds could be developed into effective postovulatory contraceptive agents.

More recently, compounds affecting progesterone metabolism or the peripheral action of progesterone have become available for clinical testing. To the former belongs epostane, a competitive inhibitor of $3 \beta$-hydroxy-steroid-dehydrogenase, which converts pregnenolone to progesterone (Pattison et al., 1985); to the latter RU486, which acts as an antiprogestin (Philibert $e t$ al., 1985). RU486 has a high affinity for the progesterone receptor and acts at the uterine target organs, i.e. the endometrium, myometrium and decidua. An effect on the release of gonadotrophins from the pituitary has also been reported (Schaison et al., 1985).

The aim of the present study was to evaluate the effect of RU486 on bleeding pattern, hormonal parameters and on endometrial morphology, when administered during the follicular or secretory phase of the menstrual cycle.

Materials and methods

\section{Subjects}

Seventeen healthy women aged 25-45 years with regular menstrual cycles (between 25 and 35 days) volunteered for the study. All subjects were of proven fertility and none of them had used steroidal contraceptives or an IUD during a minimum of 
3 months prior to the study. On admission, a gynaecological examination was performed and the volunteers were instructed to use barrier methods for contraception during the entire study period.

\section{Study design}

The study included one control, one treatment and one followup cycle. In the treatment cycle, the subjects received $50 \mathrm{mg}$ RU486 orally between 8.00 and 10.00 a.m. either on cycle days 7-10 (preovulatory phase treatment group) or on cycle days 20-23 (postovulatory phase treatment group). Seven subjects were allocated to the former group and ten to the latter group.

During the control and treatment cycle, daily morning urine was collected and kept frozen until assayed. The samples were analysed with regard to pregnanediol glucuronide $\left(P_{2}-G\right)$, oestrone glucuronide $\left(E_{1}-G\right)$, oestradiol $\left(E_{2}\right)$, progesterone $\left(P_{4}\right)$, creatinine (C) and LH. During the treatment cycle $10 \mathrm{ml}$ of blood was also taken on cycle days 4-14 and 17-27 when RU486 was given in the preovulatory and postovulatory phases respectively. The plasma was analysed with regard to cortisol. During the entire 3-month study, the subjects kept a record of uterine bleeding and side effects.

\section{Hormone assays}

The analyses of $P_{2}-G$ and $E_{1}-G$ were carried out by radioimmunological methods described by Cekan et al. (1986). LH and cortisol were estimated by radioimmunoassay assay techniques described by Sufi et al. (1986). Radioimmunoassays of $\mathrm{E}_{2}$ and $\mathrm{P}_{4}$ in urine were performed according to Beksac et al. (1984) and Beksac and Cekan (1985). In addition, the C concentration in urine was assessed by routine methods, based on the reaction of $\mathrm{C}$ with picric acid (Heinegard and Tiderström, 1973). RU486 was found not interact with the steroid measurements (S.Z.Cekan, personal communication).

\section{Calculations of hormone values}

The preovulatory phase was defined as the period from the first day of the menstrual bleeding to the day of the LH surge (inclusive), whereas the postovulatory phase was defined as the period from day $\mathrm{LH}+1$ to the day of preovulatory progesterone concentrations of less than the mean value $\pm 2 \mathrm{SD}$. All hormonal measurements in urine were expressed as $\mathrm{nmol} / \mathrm{mmol}$ creatinine (Metcalf and Hunt, 1976). The urinary steroid concentrations in each individual subject were thereafter plotted relative to either the day of the LH surge or the first day of menstruation, and the area under the curve for the corresponding time periods in the control and treatment cycles was calculated. The areas under the curve were calculated as sums of partial areas obtained according to the following formula:

area $=$ time $\times \frac{\text { level } \mathrm{a}+\text { level } \mathrm{b}}{2}+\operatorname{time} \times \frac{\text { level } \mathrm{b}+\text { level } \mathrm{c}}{2}$

etc., where time is expressed in days and $a, b$ and $c$ are the successive hormonal levels expressed in $\mathrm{nmol} / \mathrm{mmol}$ creatinine. A log normal distribution (Gaddum, 1945) was assumed for all steroid levels and areas under the curve. Paired $t$-test or analysis
Table I. Effect of oral administration of RU486 on cycle length (mean \pm SD)

\begin{tabular}{|c|c|c|c|}
\hline \multirow{3}{*}{$\begin{array}{l}\text { Treatment } \\
\text { RU486 } 50 \mathrm{mg} \text { daly }\end{array}$} & \multicolumn{3}{|c|}{ Cycle length (days) } \\
\hline & \multirow[t]{2}{*}{ Days $7-10$} & \multicolumn{2}{|l|}{ Days $20-23$} \\
\hline & & One bleeding & Two bleedings \\
\hline \multicolumn{4}{|l|}{ Control cycle } \\
\hline Follicular phase & $13.6 \pm 1.8^{4}$ & $13.2 \pm 1.5$ & $14.2 \pm 2.2$ \\
\hline Secretory phase & $12.6 \pm 2.2$ & $12.4 \pm 2.1$ & $13.0 \pm 2.2$ \\
\hline Total & $26.1 \pm 2.7^{d}$ & $25.6 \pm 2.5$ & $27.2 \pm 0.9$ \\
\hline \multicolumn{4}{|l|}{ Treatment cycle } \\
\hline Follicular phase & $21.4 \pm 3.4^{1}$ & $12.4 \pm 1.5$ & $14.0 \pm 2.2$ \\
\hline Secretory phase & $11.6 \pm 1.9$ & $11.8 \pm 1.9^{b}$ & $16.5 \pm 1.3^{b}$ \\
\hline Total & $33.0 \pm 3.7^{d}$ & $22.6 \pm 1.8^{c}$ & $305 \pm 2.6^{c}$ \\
\hline \multicolumn{4}{|l|}{ Follow-up cycle } \\
\hline Total length & $28.0 \pm 4.8$ & $26.2 \pm 1.3$ & $25.2 \pm 2.2$ \\
\hline
\end{tabular}

Values with same superscript are significantly different: ${ }^{2} P<0.01$; ${ }^{\text {b } P}<0.05$; ${ }^{\mathrm{c}} P<0.05 ;{ }^{\mathrm{d}} P<0.01$.

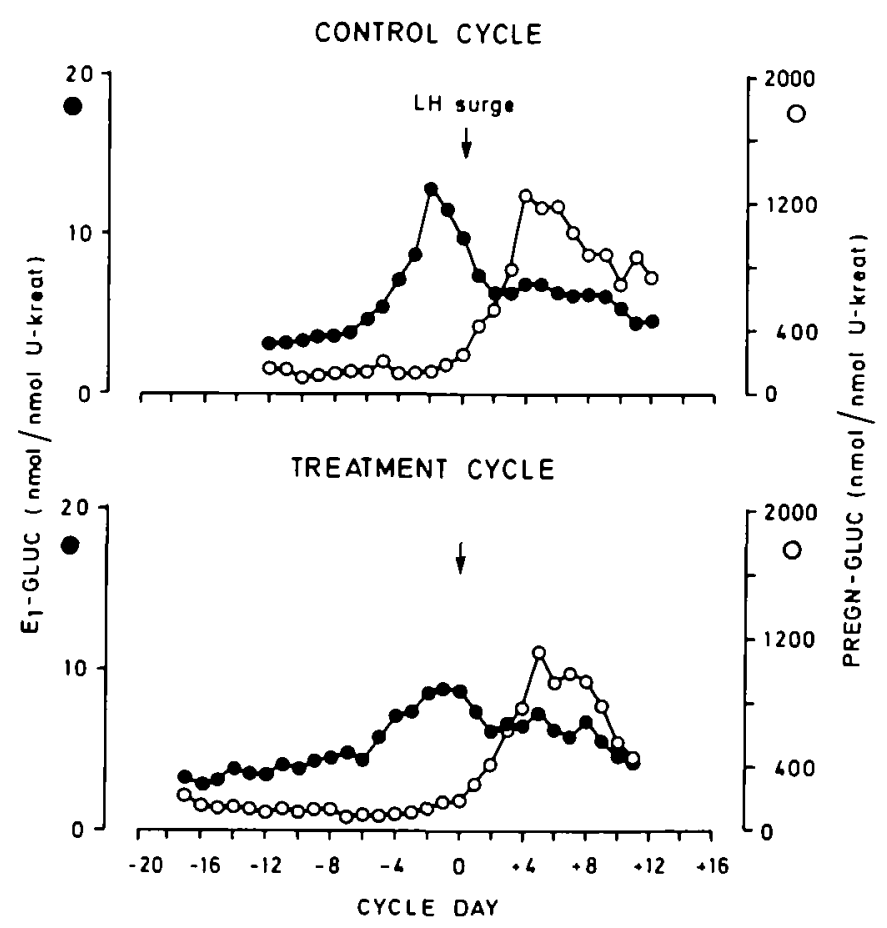

Fig. 1. Geometric mean of pregnanediol glucuronide and oestronglucuronide in morning urine during control and treatment cycle in seven patients who received $50 \mathrm{mg}$ RU486 daily on days 7-10 of the menstrual cycle.

of variance was used for the statistical evaluation of the results, except for calculating differences between length of cycle periods when the Wilcoxon two-sample Rank test was preferred.

\section{Morphological methods}

An endometrial biopsy was taken on cycle day 10 in the preovulatory phase treatment group. In the postovulatory phase treatment group the endometrial biopsy was initially planned to be taken on the 23rd day of the cycle. However, since all subjects started to bleed on the third or fourth day of RU486 intake, i.e. 
Tabte II. Hormone levels in morning unnary samples during different parts of the control and treatment cyctes

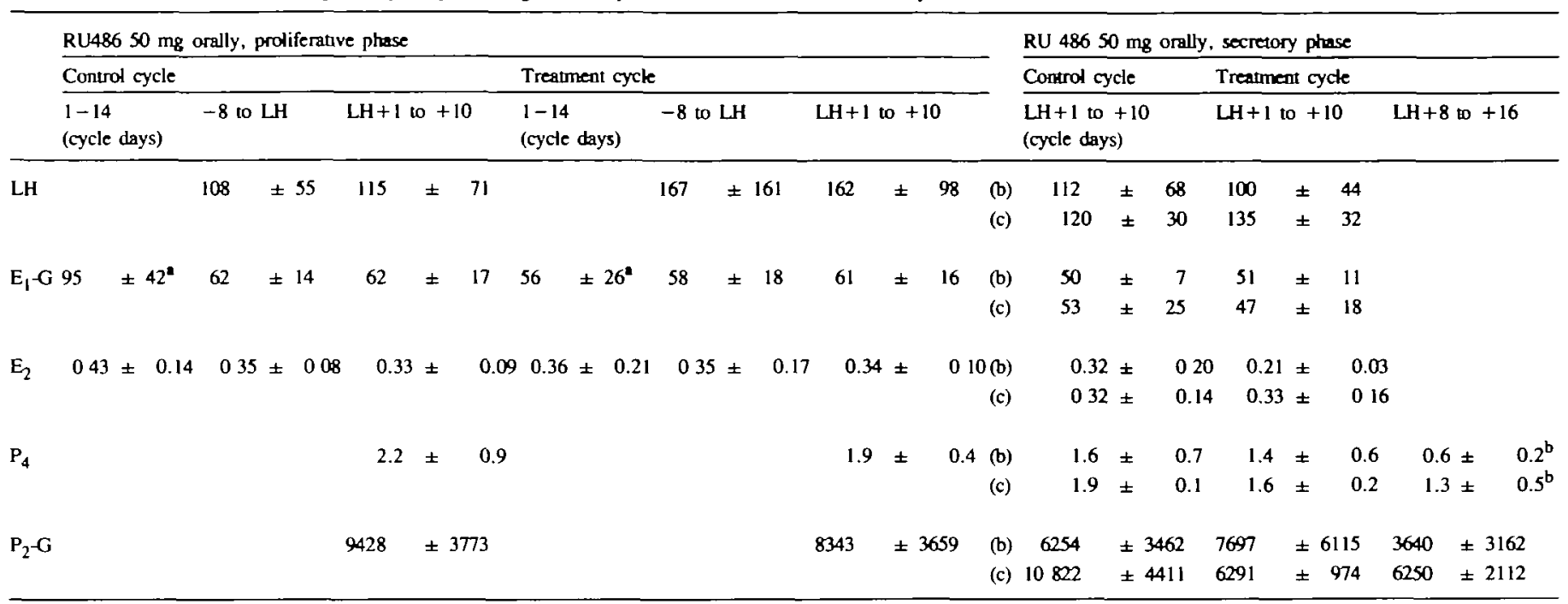

After correction for the creatinine concentration, the area under the curve was calculated and expressed in nmol/mmol creatinune, for oestrone glucuronude ( $E_{1}-G_{)}$, oestradiol $\left(E_{2}\right)$, progesterone $\left(\mathrm{P}_{4}\right)$ and pregnanediol glucuronide $\left(\mathrm{P}_{2}-\mathrm{G}\right)$ and in $I U / \mathrm{mmol}$ creatinune for $\mathrm{LH}$.

The values are mean $\pm S D$

Values with same superscrup are significantly different: ${ }^{2} P<005$; ${ }^{\text {b }} P<005$.

Subjects with one (b) and two (c) btceding episodes.

on day 22 or 23 of the cycle, the biopsies from the women were taken either before the bleeding (cd 21;2 subjects), at start of bleeding (cd 23;4 subjects) or after the bleeding had stopped (cd $25,26,27 ; 3$ subjects).

Specimens were taken with a Randall curette from the anterior and lateral walls of the uterine cavity without prior cervical dilatation or local anaesthesia. The biopsy material was immediately fixed in Bouin's solution and used for light microscopic examination after embedding in paraffin and staining with haematoxylin.

The material prepared for light microscopy was assessed by morphometric analyses $(\times 400)$ measuring the number of glands $/ \mathrm{mm}^{2}$, number of glandular and stromal mitoses $/ 1000$ glandular and stromal cells respectively, glandular diameter, cells with basal vacuolation/1000 glandular cells and glandular epithelial height (Johannisson et al., 1987).

The study was approved by the Swedish Drug Regulatory Authorities and the Ethical Committee of the Karolinska Hospital.

\section{Results}

\section{Preovulatory group}

None of the seven subjects treated during the preovulatory phase of the menstrual cycle started to bleed during treatment. In all subjects the treatment cycle $(33.0 \pm 3.7$ days; mean $\pm S D)$ was significantly $(P<0.05)$ prolonged in comparison with the control cycle $(26.1 \pm 2.4$ days). The hormonal data showed that the prolongation of the treatment cycle was due to a significantly longer preovulatory phase $(21.4 \pm 3.4$ days $)$ than in the control cycle $(13.6 \pm 1.8$ days $)(P<0.05)$. The subsequent postovulatory phase was of normal length (Table I). The urinary concentration of $E_{1}-G$ during the first 14 days of the cycle was significantly lower during the treatment than during the control cycle. However, when the urinary levels of $P_{2}-G, P_{4}, E_{2}, E_{1}-G$

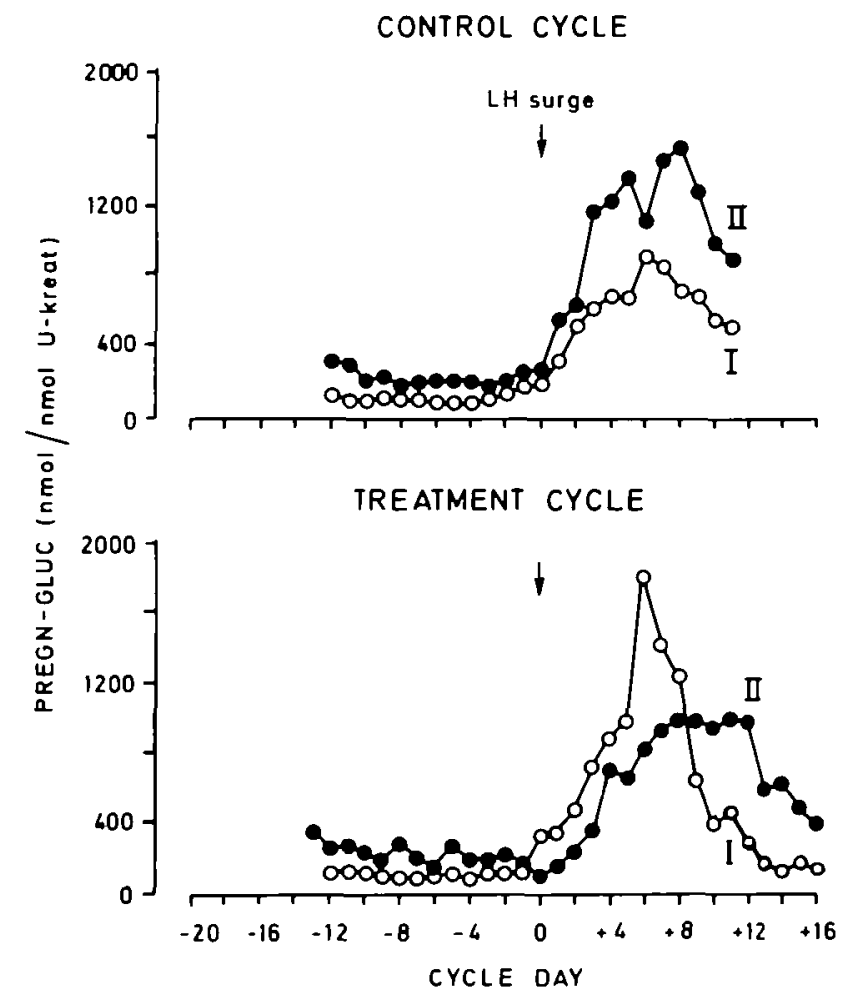

Fig. 2. Mean levels of pregnanediol glucuronide in morning urine during control and treatment cycle in nine patients treated with RU486 $25 \mathrm{mg}$ twice daily on cycle days $20-23$. Five patients (I) had only one bleeding, occurring on the 3rd day of treatment. Four patients (II) in addition to bleeding during treatment experienced bleeding $\sim 1$ week later.

and $\mathrm{LH}$ during cycle days $\mathrm{LH}-8$ to $\mathrm{LH}$ peak and $\mathrm{LH}+1$ to $\mathrm{LH}+10$ in the treatment cycle were compared with those in the control cycle, no differences were found (Figure 1, Table II). 
Thus, the reason for the longer preovulatory phase was a delay in the oestrogen and LH surges. Once the oestrogen concentration started to increase, the remaining part of the cycle seemed hormonally normal. The length of the follow-up cycle was also normal.

Five of the seven women provided sufficient biopsy material for light microscopic assessment. In two women the biopsy specimen was too small for morphometric analysis. The light microscopic appearance of the endometrium was identical to that found in the normally menstruating woman (Johannisson et al., 1987), indicating that treatment with RU486 during the proliferative phase of the cycle does not alter endometrial morphology.

\section{Postovulatory group}

Ten subjects were treated in the postovulatory phase, but one

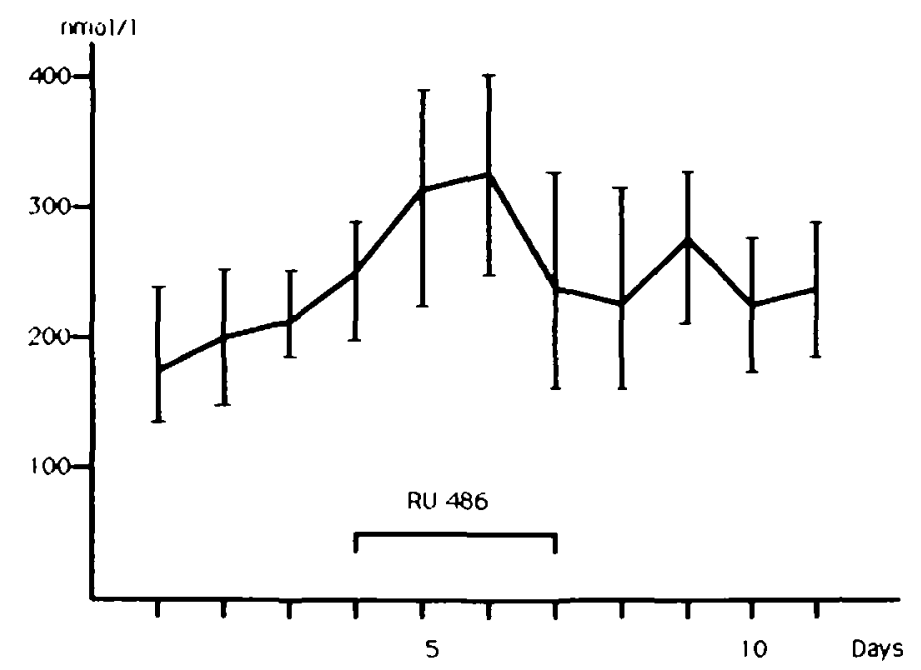

Fig. 3. Plasma cortisol levels before, during and after oral administration of $50 \mathrm{mg}$ RU486 daily for 4 days in 16 non-pregnant women. The values are geometric means $\pm 95 \%$ confidence limits. of them was excluded since the hormonal analyses revealed that the woman had had a late ovulation and in fact had been treated during the preovulatory period. The remaining nine women started to bleed on the 3rd or 4th day of treatment. In four subjects the induced bleeding was followed by a second bleeding episode at approximately the expected time of their normal menstruation. In the remaining five subjects, the next bleeding did not occur until $\sim 4$ weeks later as shown in Table I. In the women who had two bleeding episodes the RU486 treatment started on days 4, 5, 6 and 9 after the LH surge and in those with only one bleeding episode RU486 intake started on days 6, 7, 7, 8 and 11 after the LH surge.

Based on urinary progesterone concentration, the secretory phase was $11.8 \pm 1.9$ days for the group with one bleeding episode and $16.5 \pm 1.3$ days for the group with two bleeding episodes $(P<0.05)$. The duration of the follow-up cycles did not differ from the corresponding control cycles (Table I).

The concentration of $\mathrm{P}_{4}$ during and after treatment with RU486 ( $\mathrm{LH}+8$ to $\mathrm{LH}+16$; median starting day of RU486 treatment $\mathrm{LH}+7$ ) was also significantly lower in the group with one bleeding episode. However, in the earlier part of the secretory phase $(\mathrm{LH}+1$ to $\mathrm{LH}+10)$, there were no differences in the hormonal levels between the two treatment groups, or between these and the corresponding parts of the control cycle (Figure 2, Table II).

Plasma cortisol concentration showed a slight but significant increase $(P<0.05)$ during RU486 treatment when compared with the values before and after the RU486 administration (Figure 3).

Seven of the nine biopsies provided sufficient endometrial material for a complete light microscopic morphometric assessment (Table III).

Correlated to the LH surge, the biopsies during the postovulatory phase were taken on $\mathrm{LH}+7$ (one subject), $\mathrm{LH}+8$ (two subjects), $\mathrm{LH}+10$ (one subject), $\mathrm{LH}+12$ (two subjects) and $\mathrm{LH}+11,+13$ and +17 (one subject each). In two women only

Tabłe III. The effect of RU486 on the endometrium when administered during cycle days 20-23

\begin{tabular}{|c|c|c|c|c|c|c|c|c|c|c|}
\hline Subject & $\begin{array}{l}\text { No. of } \\
\text { glands } / \mathrm{mm}^{2}\end{array}$ & $\begin{array}{l}\text { Glandular } \\
\text { mitoses } \\
1000 \text { cells }\end{array}$ & $\begin{array}{l}\text { Stroma } \\
\text { mitoses/ } \\
1000 \text { cells }\end{array}$ & $\begin{array}{l}\text { Glandular } \\
\text { diameter } \\
(\mu \mathrm{m})\end{array}$ & $\begin{array}{l}\text { No. of } \\
\text { vacuolated } \\
\text { cells/1000 } \\
\text { cells }\end{array}$ & $\begin{array}{l}\text { Glandular } \\
\text { epithelial } \\
\text { height ( } \mu \mathrm{m})\end{array}$ & $\begin{array}{l}\text { Leukocytic } \\
\text { infiltration }\end{array}$ & Datıng & $\begin{array}{l}\text { Time of } \\
\text { cycle at } \\
\text { biopsy }\end{array}$ & $\begin{array}{l}\text { Time of } \\
\text { biopsy from } \\
\text { RU486 start } \\
\text { (days) }\end{array}$ \\
\hline
\end{tabular}

\begin{tabular}{|c|c|c|c|c|c|c|c|c|c|c|}
\hline \multicolumn{11}{|l|}{ Group (b) } \\
\hline RA & - & 0 & 0 & -2 & 0 & 24.5 & 3 & Menstrual & $\mathrm{LH}+\mathbf{1 0}$ & 4 \\
\hline $\mathbf{M H}$ & 11.4 & 0 & 0 & 70.7 & - & 15.5 & 0 & Late secretory & $\mathrm{LH}+8$ & 2 \\
\hline $\mathrm{CL}$ & 19.4 & 0 & 3 & 68.7 & 0 & 19.2 & 0 & Late secretory & $\mathbf{L H}+12$ & 2 \\
\hline GJ & 27.5 & 0 & 0 & 18.7 & 0 & 16.2 & 3 & Menstrual & $\mathrm{LH}+12$ & 7 \\
\hline MR & -1 & 0 & 0 & -2 & 0 & 18.0 & 3 & Menstrual & $\mathrm{LH}+11$ & 4 \\
\hline $\begin{array}{l}\text { Mean } \pm S D \\
\text { or range }\end{array}$ & $19.4 \pm 8.0$ & 0 & $0-3$ & $52.7 \pm 29.5$ & 0 & $15.1 \pm 8.5$ & $0-3$ & & & \\
\hline \multicolumn{11}{|l|}{ Group (c) } \\
\hline CA & 39.5 & 1 & 0 & 45.0 & 0 & 18.5 & 2 & Premenstrual & $\mathrm{LH}+7$ & 4 \\
\hline GG & 26.1 & 0 & 0 & 44.0 & 0 & 17.0 & 2 & Menstrual & $\mathrm{LH}+8$ & 4 \\
\hline AJ & 8.0 & 3 & 1 & 53.7 & 130 & 22.2 & 1 & $\begin{array}{l}\text { Irregular secretory } \\
\text { activity }\end{array}$ & $\mathrm{LH}+13$ & 8 \\
\hline MK & 19.4 & 26 & 1 & 46.0 & 70 & 26.0 & 0 & Proliferative phase & $\mathrm{LH}+17$ & 9 \\
\hline
\end{tabular}

Group (b) one bleeding episode; group (c) two bleeding episodes.

-Material too regressive to be assessed. 
a partial assessment could be made because the endometrial material had undergone strong regression. In these cases the glands had either collapsed or showed a partial breakdown and the number and diameter of the glands therefore could not be assessed.

In three of the five women with a single bleeding episode, the endometrium showed regressive changes as well as bleeding and a heavy infiltration of leukocytes. The biopsies in these three cases were taken on day 4 of RU486 treatment and were compatible with the structure observed during normal menstruation. In the remaining two subjects with one single bleeding episode, the biopsies were obtained on day 2 of RU486 treatment. In these women the histological pattern corresponded to the late postovulatory phase of a normal cycle and showed early regression changes.

In two of the four women with two bleeding episodes the biopsy was taken on the fourth day of RU486 treatment. In both subjects a situation corresponding to premenstrual and menstrual phase was observed. It is noteworthy that these regressive changes, which usually do not occur before $\mathrm{LH}+12$ of the normal menstrual cycle, were observed already on days $\mathrm{LH}+7$ and +8 . In the two other women the biopsy was taken on either the 13th or the 17th day after the LH surge, when the first bleeding episode had stopped. In one woman, the endometrium showed irregular secretory changes suggesting a persistent effect of progesterone, and, in the other, proliferative changes were observed, with high mitotic activity of the glands.

\section{Discussion}

The results of the present study indicate that a 4-day administration of $50 \mathrm{mg}$ RU486 starting from the 4th day or later after the LH peak invariably resulted in uterine bleeding on the 3 rd or 4th day of treatment, whereas the same treatment did not have any effect on the endometrium when given on cycle days $7-10$ of the preovulatory phase. However, the latter treatment regimen prolonged the duration of the preovulatory phase and delayed the oestrogen rise and $\mathrm{LH}$ surge. It is noteworthy that, once follicular development resumed, the magnitude of the oestrogen rise and LH peak, as well as duration and hormonal levels of the postovulatory phase, were similar to those found in the control cycles.

The delay of the preovulatory oestradiol rise as well as the LH surge could be due to an effect of RU486 either on the hypothalamic-pituitary axis influencing the release of gonadotrophins, or directly on the follicle. To what extent RU486 affects the release of gonadotrophins (if administered during the preovulatory phase of the cycle) is unclear. Such an effect could not be demonstrated in the monkey (Healy et al., 1983; Asch and Rojas, 1985). On the other hand, RU486 administered to normal women, in the mid-luteal phase of the menstrual cycle (Schaison et al., 1985) and to postmenopausal women (Gravanis et al., 1985), resulted in a decrease in mean LH levels and the disappearance of pulsatile release. It is noteworthy, however, that in women with anovulatory cycles no effect on LH could be observed (Schaison et al., 1985).

It is well known that hormonal production of granulosa cells is of major importance for the regulation of follicular maturation
(McNatty, 1981). Studies in vitro on human granulosa cells isolated from follicular fluid and mature follicles, have shown that the addition of RU486 causes significant suppression of progesterone production by decreasing the activity of $3 \beta$-hydroxy steroid dehydrogenase (Dimattina et al., 1986). As recent studies indicate that substantial amounts of the compound can be found in follicular fluid (A.A.Templeton et al., in preparation), following oral administration of RU486, and human ovarian progesterone receptors are present in the granulosa cells (Jacobs et al., 1980), it is at least possible that RU486 may directly influence follicular maturation either by a temporary halt or by a premature follicular disruption. In the latter case ovulation will be delayed until a new leading follicle has been recruited.

Except for the delay in the development of the LH peak and of the maximal levels of urinary oestradiol, the adminstration of RU486 in the preovulatory phase did not seem to have any significant effect. None of the subjects in the preovulatory phase treatment group started to bleed during or immediately after the tablet intake. The morphometric analysis of the light microscopic material did not differ from the findings of the endometrial biopsies taken from untreated women in the corresponding period of the cycle.

When $50 \mathrm{mg}$ RU486 was administered during the postovulatory period on cycle days 20-23, all patients started to bleed on the third or fourth day of treatment. In five patients, the bleeding was similar to that of normal menstruation, while in the remaining four patients, the bleeding was more scanty and was followed by a second bleeding episode at approximately the expected time of menstruation. The time interval from the $\mathrm{LH}$ surge to the day progesterone levels reached preovulatory values was significantly shorter in the women with one bleeding episode than in the subjects with two bleeding episodes. In the first group of subjects the progesterone decrease occurred during RU486 intake. In the second group of subjects the progesterone levels remained unchanged until the second bleeding episode.

The effect of RU486 on the bleeding pattern could be due to an effect on the endometrium, on corpus luteum function and/or on the hypothalamic pituitary system. Several investigations indicate that the local effect on the endometrium is the most important. RU486 has a high affinity for the uterine progesterone receptor and antagonizes the effect of progesterone on the endometrium (Herrmann et al., 1985; Philibert et al., 1985). Furthermore, Croxatto et al. (1985) demonstrated in the human female, and Asch and Rojas (1985) in the rhesus monkey, that RU486 provoked bleeding which occurred in spite of high progesterone levels during pseudopregnancy induced by HCG administration. Nevertheless, the shorter duration of the postovulatory phase and the premature decrease of progesterone in the subjects with one bleeding episode, compared with the subjects with two bleeding episodes, indicate that RU486 can also influence luteal function either directly or through an effect on pituitary gonadotrophin secretion. The results of Schaison et al. (1985) support both these alternatives; i.e. the drug may impair, simultaneously or separately, luteal function and gonadotrophin secretion in a dosedependent manner. Studies in vitro also indicate that RU486 may have a direct effect on the progesterone production of human granulosa cells (Dimattina et al., 1986). The variation in response to RU486 treatment could depend upon the age of the corpus 
luteum. The finding that the women with two bleeding episodes tended to have been treated earlier in relation to the $\mathrm{LH}$ surge than those with one bleeding episode supports such a possibility. It is well known that several characteristics of the corpus luteum are modified during the normal postovulatory phase of the menstrual cycle including morphological changes (Corner, 1956), a decrease in the number of LH receptors (Yamoto et al., 1986), and an increase in LH inhibitory protein (Nakano et al., 1985).

It has been suggested that besides a local effect on the endometrium, RU486 influences the release of LH (Baulieu, 1985). Schaison et al. (1985) have reported, as mentioned previously, decreased LH levels and the disappearance of the pulsatile pattern in a dose-dependent way when women were treated with RU486 in mid-luteal phase. In the present study the mean LH level was unaffected during RU486 treatment on days 20-23 of the menstrual cycle. These findings are in agreement with those of Asch and Rojas (1985) in the rhesus monkey and of Croxatto et al. (1987) in the human female, who could not demonstrate any decrease in mean gonadotrophin levels. However, in neither of the above-mentioned studies nor in this was the experimental design suitable for measuring the pulsatile release of $\mathrm{LH}$.

Besides an antiprogestin effect, RU486 also has antiglucocorticoid activity. An increase in plasmid cortisol levels has been reported previously during treatment with RU486 in women in early pregnancy (Kovacs et al., 1984). The present study indicates that the same is also true in non-pregnant women. The increase was, however, slight and the concentrations of plasma cortisol never exceeded normal limits. Similar results have also been reported by Croxatto et al. (1985) but not by Schaison et al. (1985). The reason for this discrepancy remains to be elucidated.

In the present study the light microscopic examination of the biopsies obtained on day 4 of the RU486 administration did not reveal any significant effect on the endometrium, when the compound was given in the proliferative phase. This is somewhat contradictory to the findings of Koering et al. (1986) in the endometrium of castrated oestradiol-treated monkeys. These authors claimed that RU486 had a weak progestational effect on the proliferative endometrium. The difference may be explained by the fact that the design of the experiment was different, but it is also likely that species difference may play a role. Chillik et al. (1986) carried out experiments in non-castrated monkeys, giving the RU486 in the mid-luteal phase. Their results were similar to ours and regressive changes were reported to occur in the endometrium with a uniform shedding of the mucosa and subsequent bleeding. As in the monkeys, the endometrial bleedings occurred within $48 \mathrm{~h}$ and $96 \mathrm{~h}$ after the RU486 administration. In the monkeys the shedding of the endometrium was considered to be quite deep. The present study was, however, carried out in thin endometrial strips representing only the upper functional layer. This part of the human endometrium had undergone a complete regression of the mucosa with a strong leukocytic infiltration on the 4th day of the administration. It is noteworthy that this strong regression and complete shedding of the endometrium also occurred on the 4th day of the RU486 treatment in women having two bleeding episodes. The presence of the second bleeding episode is therefore difficult to explain. In one woman, the endometrial biopsy was taken after the bleeding had stopped. In this case a proliferation was found, suggesting the commencement of a new endometrial cycle. In another case the biposy was also obtained after the bleeding had stopped and the mucosa revealed an abnormal secretory activity. In this case some midluteal-phase endometrium may have been conserved, perhaps due to high progesterone values, and the second bleeding episode resulted in a more complete shedding. This hypothesis, however, is contradicted by the study of Chillik et al. (1986) in cynomolgus monkeys where the shedding of the endometrium was found to be uniform in the entire uterus. The results of the present study do not allow any definite conclusions in this respect.

In view of the fact that RU486 acts as a strong antiprogestin at the receptor level, further in-depth studies may be of importance into factors mediating the effect on the pituitary and ovarian activity, the endometrium and the onset of endometrial bleeding. Such studies may facilitate the future possible clinical use of the antiprogestin to prevent implantation and for termination of very early pregnancy.

\section{Acknowledgements}

We are indebted to Drs Paul F.A.Van Look and A.Ullman who made many valuable suggestions during the preparation of the manuscript. The expert technical assistance of Ms Ingrid Vedin and Mrs Astrid Häggblad of Stockholm, Mrs Erika Jakobsson-Ström and Mrs Fabienne Simon of Geneva, is gratefully acknowledged. The present study was supported by the WHO Special Programme of Research, Development and Research Training in Human Reproduction, Geneva, Switzerland, and by the Swiss National Research Foundation, grant 3.955-0.84. The compound RU486 was kindly supplied by Roussel Uclaf, Paris, France.

\section{References}

Asch,R.H. and Rojas,F.J. (1985) The effect of RU486 on the luteal phase of the rhesus monkey. J. Steroid Biochem., 22, 227-230.

Baulieu,E.E. (1985) RU486: an antiprogestin steroid with contragestive activity in women. In Baulieu,E.E. and Segal,S.J. (eds), The Antiprogestin Steroid RU486 and Human Fertility Control. Plenum Press, New York, pp. 1-26.

Behrman,H.R. (1979) Prostaglandins in hypothalamo-pituitary and ovarian function. Annu. Rev. Physiol., 41, 685-700.

Beksac,M.S. and Cekan,S.Z. (1985) Reliability of progesterone measurements in urine. J. Clin. Chem. Clin. Biachem., 23, 183-186.

Beksac,M.S., Wang,Y. and Cekan,S. (1984) Validity of the radioimmunoassay of unconjugated estradiol in urine. Acta Reprod. Turcica, $5,55-62$.

Bergquist,C., Nillius,S.J. and Wide,L. (1980a) Effects of a luteinizing hormone-releasing hormone agonist on luteal function in women. Contraception, 22, 287-293.

Bergquist,C., Nillius,S.J. and Wide,L. (1980b) Luteolysis induced by a luteinizing hormone-releasing hormone agonist is prevented by human chorionic gonadotrophin. Contraception, 22, 341-347.

Cekan,S.Z, Beksac,M.S,. Wang,E., Shi,S., Masironi,B., Landgren, B.-M. and Diczfalusy,E. (1986) The prediction and/or detection of ovulation by means of urinary steroid assays. Contraception, 33, $327-345$.

Chillik,C.F., Hsiu,J.G., Acosta,A.A., van Uem,J.F.H.M. and Hodgen,G.D. (1986) RU486-induced menses in cynomolgus monkeys: uniformity of endometrial sloughing. Fertil. Steril., 45, 708-712.

Corner,G.W.,Jr (1956) Histologic dating of corpus luteum of menstruation. Am. J. Anat., 98, 377-401. 
Croxatto,H.B., Spitz,I.M., Salvatierra,A.M. and Bardin,C.W. (1985) The demonstration of the antiprogestin effects of RU486 when administered to the human during hCG-induced pseudopregnancy. In Baulieu,E.E. and Segal,S.J. (eds), The Antiprogestin Steroid RU486 and Human Fertility Control. Plenum Press, New York, pp. 263-269.

Croxatto,H.B., Salvatierra,A.M., Romero,C. and Spitz,I.M. (1987) Late luteal phase administration of RU486 for three successive cycles does not disrupt bleeding patterns or ovulation. J. Clin. Endocrinol. Metab., 65, 1272-1277.

Dimattina,M., Albertson,B., Seyler,D.E., Loriaux,D.L. and Falk,R.J. (1986) Effect of the antiprogestin RU486 on progesterone production by cultured human granulosa cells: inhibition of the ovarian $3 \mathrm{~B}$ hydroxy steroid dehydrogenase. Contraception, 34, 199-206.

Gaddum,J. (1945) Lognormal distributions. Nature, 156, 463-466.

Gravanis,A., Schaison,G., George,M., de Brux,J., Stayaswaroop,P.G., Baulieu,E.E. and Robel,P. (1985) Endometrial and pituitary response to the steroidal antiprogestin RU486 in postmenopausal women. $J$. Clin. Endocrinol. Metab., 60, 156-163.

Healy,D.L., Chrousos, G.P., Shulte,H.M., Williams,R.F., Gold,P.W., Baulieu,E.E. and Hodgen,G.D. (1983) Pituitary and adrenal responses to the anti-progesterone and anti-glycocorticoid steroid RU486 in primates. J. Clin. Endocrinol. Metab., 57, 863-865.

Heinegard,D. and Tiderström,G. (1973) The determination of serum creatinine by a direct colorimetric method. Clin. Chim. Acta, 43, $305-310$.

Hermmann, W.L., Schindler,A.M., Wyss,R. and Bishof,P. (1985) Effects of the antiprogesterone RU486 in early pregnancy and during the menstrual cycle. In Baulieu,E.E. and Segal,S.J. (eds), The Antiprogestin Steroid RU486 and Human Fertility Control. Plenum Press, New York, pp. 179-198.

Jacobs,B.R., Suchocki,S. and Smith,R.G. (1980) Evidence for a human ovarian progesterone receptor. Am. J. Obstet. Gynecol., 138, $332-336$

Johannisson,E., Landgren,B.-M., Rohr,H.P. and Diczfalusy,E. (1987) Endometrial morphology and peripheral hormone levels in women with regular menstrual cycles. Fertil. Steril., 48, 401-408.

Koering,M.J., Healy,D.L. and Hodgen,G.D. (1986) Morphologic response of endometrium to a progesterone receptor antagonist, RU486, in monkeys. Fertil. Steril., 45, 280-287.

Kovacs,L., Sas,M., Resch,B.A., Ugocsai,G., Swahn,M.L., Bygdeman,M. and Rowe,P.J. (1984) Termination of very early pregnancy by RU486, an antiprogestational compound. Contraception, 29, 399-410.

McCracken,J.A., Carlson,J.C., Glew,M.E., Godnig,J.R., Baird,D.T., Green,K. and Samuelsson,B. (1972) Prostaglandin identified as a luteolytic hormone in sheep. Nature, 238, 129-134.

McNatty,K.P. (1981) Hormonal correlates of follicular development in the human ovary. Aust. J. Biol. Sci., 34, 249-268.

Metcalf,M. and Hunt,E.G. (1976) Cakculation of estrogen excretion rates from urinary estrogen to creatinine ratios. Clin. Biochem, 9, 75-77.

Nakano,R., Iwasaki,M. and Yamoto,M. (1985) Luteinizing hormone receptor binding inhibitor in aqueous extract of human corpus luteum. Gynecol. Obstet. Invest., 20, 45-51.

Pattison,N.S., Webster,M.A., Phipps,S.L., Anderson,A.B.M. and Gillmer,M.D.G. (1985) Inhibition of $3 \beta$-hydroxy steroid dehydrogenase activity in first and second trimester human pregnancy and the luteal phase using Epostane. Fertil. Steril., 42, 875-881.

Pharris,B. (1971) Prostaglandin induction of luteolysis. Proc. NY Acad Sci., 180, 434-444.

Philibert,D., Moguilewsky,M., Mary,I., Lecaque,D., Tournemine,C., Secchi,J. and Deraedt,R. (1985) Pharmacological profile of RU486 in animals. In Baulieu,E.E. and Segal,S.J. (eds), The Antiprogestin Steroid RU486 and Human Fertility Control. Plenum Press, New York, p. 49.

Schaison,G., George,M., Lestrat,M., Reinberg,A. and Baulieu,E.E.
(1985) Effects of the antiprogesterone steroid RU486 during midluteal phase in normal women. J. Clin. Endocrinol. Metab., 61, 484-489.

Sufi,S.B., Donaldson,A. and Jeffcoate,S.L. (1986) Method Manual. WHO Programme for the Provision of Matched Assay Reagents, 10th edn., Geneva, Switzerland.

Yamoto,N., Nakano,R., Iwasaki,M., Ikoma,H. and Furukawa,K. (1986) Luteinizing hormone receptors in human ovarian follicles and corpora lutea during the menstrual cycle. Obstet. Gynecol., 68, 200-203.

Received on December 16, 1987; accepted on April 12, 1988. 